\title{
LANDSCAPE METRICS AS A TOOL FOR EVALUATION LANDSCAPE STRUCTURE - CASE STUDY HUSTOPEČE
}

\author{
Lenka Tlapáková1 ${ }^{1}$ Dagmar Stejskalová ${ }^{2}$, Petr Karásek $^{3}$, Jana Podhrázká ${ }^{4}$
}

Received 11 November 2011; Accepted 22 October 2012

\begin{abstract}
The contribution presents the method of evaluation of rural landscape development in Hustopeče microregion by means of the analysis of landscape structure. Based on the computation of the values of landscape ecological indexes, development and typical and specific features in selected time horizons are interpreted. The time of the stable cadastre mapping (1825) was chosen as the initial period, other periods were the actual situation at present (2006) and the time between these two periods (the sixties of the $20^{\text {th }}$ century). It is an agricultural landscape in southern Moravia used for intensive farming. Analysis results illustrate long-term continuing landscape utilization for agricultural production. All evaluative indexes indicate reduction of number of patches and edge effect, enlarging of patch area and, consequently, increasing of geometrical extent and coarse-grained landscape pattern.
\end{abstract}

Keywords: landscape structure, metric analyses, Land Use, Land Cover, GIS, stable cadastre, aerial photographs

\section{Introduction}

Processes in landscape, its functions and character are related to the configuration of landscape, its arrangement and actual situation. Landscape structure has a crucial influence on functional characteristics of landscape. Any change in landscape structure, both spatial and temporal ones, influences the course of energy and material flows, passability and habitability of landscape, its ecological stability and other properties and characteristics. If we solve urgent problems of landscape and its protection in the future, our solution should not be based on the present situation but it should be derived from available reliable historical materials describing the trends of landscape development. Taking into account a legacy of the past (radical change in the spatial arrangement of landscape structure, resulting in the flattening of landscape functions) and fluctuations of temperatures and precipitation in the last years, non-

\footnotetext{
1 RNDr. Lenka Tlapáková, Ph.D., Research Institute for Soil and Water Conservation, B. Němcové 2625,53002 Pardubice, e-mail: tlapakova.lenka@vumop.cz

2 Ing. Dagmar Stejskalová, Research Institute for Soil and Water Conservation, Lidická 25/27, 60200 Brno, e-mail: stejskalova.dagmar@vumop.cz

${ }^{3}$ Mgr. Petr Karásek, Research Institute for Soil and Water Conservation, Lidická 25/27, 60200 Brno, e-mail: karasek.petr@vumop.cz

${ }^{4}$ Ing. Jana Podhrázská, Ph.D., Research Institute for Soil and Water Conservation, Lidická 25/27, 602 00 Brno, email: podhrazska.jana@vumop.cz
} 
production landscape functions, landscape accessibility, and last but not least, landscape aesthetics are increasingly accentuated.

However, the experience with the present proposals of land use plans and land consolidation indicates that the materials that would provide information on landscape arrangement and its time-proven development are not used either for the proposals of new functional land use or for the implementation of proposed measures. The landscape was not "fragmented" either functionally or spatially in the past to such an extent as it is evident from the present landscape studies, i.e. it is divided into functionally separated parts. In ancient times (before the introduction of large-scale production) the landscape structure determined the ways of landscape use while at present the situation is reversed, production activities mould the landscape according to their needs. If we want to renew the essential feature of landscape its multi-functionality, its planning should be based on the knowledge of its development both in general and specific aspects of particular territories.

Rural landscape is exposed to waves of social changes when "traditional approaches" are replaced by "modern ones", when the rural space is altered into a production one, which often brings about irreversible losses of open landscape that is unique on the European scale due to its diversity, composition, small cultural artifacts and genius loci.

The analysis of landscape structure and characteristic values obtained from this analysis allows deriving developmental trends and significant landscape changes in analysed territories. The interpretation of these trends in the context of the knowledge of historical development (social, political and economic conditions) provides an important source of information for influencing the development and planning in the years to come.

The observation of historical changes in landscape in the time horizons of tens to hundreds years is the observation of exclusively anthropic changes. Anthropogenic processes influence landscape appearance, structure and functions directly (opencast mining, construction, ploughing, etc.) and indirectly by affecting the intensity and course of natural processes (erosion, water regime, cycle of matter and energy flow, etc.).

Changes in landscape structure, e.g. grasslands put under the plough, interruption or liquidation of local corridors, great enlargement of fields (landscape grains), road construction (causing landscape fragmentation and barrier effect), directly influence the movement of organisms in landscape and e.g. erosion processes, retention capacity of landscape or water runoff regime.

Overall changes in landscape, especially in the way of land use and in structure, are monitored very significantly by a time series of aerial photographs.

Aerial photogrammetry for military purposes, used in the CR territory in regular intervals since the end of the $30 \mathrm{~s}$ to $40 \mathrm{~s}$ of the $20^{\text {th }}$ century, has been an irreplaceable source of data on temporal landscape changes (Guth, Kučera, 1997; www.nature.cz).

Analysis of the spatial distribution of landscape structural elements, information on the area structure of landscape elements, on their representation and proportions in very exact ground plan projection are among the most frequently used interpretations of aerial photographs. From the aspect of landscape evaluation the application of general information concerning the spatial structure of vegetation, land areas, settlements and settlement units in landscape, roads, watercourses, line technical elements, structure of scattered green vegetation and production activities in landscape (Juhás, 1991) is very important.

The contribution and application of data from the Earth remote sensing to landscape planning and conservation consist mainly in the inventory and determination of the actual situation of elements of interest; thanks to the time series it is possible to monitor developmental changes and to improve the proposals of essential conservation and management measures. Among publications dealing with the Earth remote sensing in nature and landscape conservation the article "Evaluation of changes in landscape using the Earth remote sensing" (Hais, Brom, Pecharová, 2006) should be cited in which methods of remote sensing, its pros and cons are described. 
Historical maps at a suitable scale (e.g. stable cadastre, military maps) and contemporary maps (cadastral maps, basic map, satellite and aerial photographs, etc.) belong to graphical materials that cannot be omitted in research on changes in open landscape. The materials of ERS are the most suitable material for the $2^{\text {nd }}$ half of the $20^{\text {th }}$ century documenting the detailed development of landscape structure (Lipský, 2000).

The information potential of historical maps is convenient for the study of landscape from various aspects and for different landscape types. Possibilities of the application of these materials are documented by a number of realized researches on changes in landscape and landscape structure, e.g. revitalization of the landscape cover of the High Tatras Mts. after a wind disaster (Boltiziar, Bruna, Krovakova, 2008), monitoring of the horizontal landscape structure development in a selected time segment (Kubeš, Mičlová, 2003), changes in land use from the aspect of ongoing succession and anthropogenic processes (Spulerova, 2008), including the processing by GIS tools (Girel, Garguet-Duport, Pautou, 1997; Xu Jian-hua, Lu Yan, Ai Nan-shan, Yue Wen-ze, 2001).

A possible landscape evaluation is the use of so called indicators - these are indicators that simplify the range of quantitative data and phenomena and contribute to a reduction in the number of variables with the same informative capacity. The method of landscape evaluation by means of indicators is very suitable for the assessment of landscape structures and functions and other phenomena (Lipský, Romportl, 2006; Pérez-Soba, Wascher, 2005). From an international aspect it is necessary to cite a publication that determines the direction of the present approach to landscape, its conservation, planning and landscaping in a significant way. The components of landscape (structures) and their quality - forests, pastures, gardens, permanent grasslands (PGL), arable land, water bodies, water-courses, and other areas are determinant factors of landscape functions. The landscape function reflects the relationships among the particular landscape components. Therefore certain criteria of evaluation of correlations between the components of landscape and its functions are necessary. Landscape evaluation is based on so called matrices - areas that in landscape take up the most important (the largest) part of the landscape in question (Forman, Godron, 1993; Fladmark, Mulvagh, Evans, 1991; Zonneveld, 1979).

Analogical studies focused on land use change by means of similar tools and input data (landscape metrics, remote sensing, GIS) are created for different types of landscapes (open x urbanized) of different areas (watershed $x$ city) in different parts all over the world (Delin, Bicheng, Xianzhao, et al., 2011).

These analyses are generated with a view to change trends from the past till the presence, and herewith to the assumption that current trends would continue in the future. (Oguz, Zengin, 2011; Zhang, Kong, Sun, et al., 2010). FRAGSTAT software - spatial pattern analysis program for quantifying landscape structure, enabling determination of landscape metrics at class or landscape level (Oguz, Zengin, 2011; Wang, Yin, 2011; Kamusoko, Aniya, 2007) is used

Landscape structure analysis in time are also applying for planning of specific management of special protected areas based on comparing of their development and development of the surrounding unprotected landscape (Hayriye, Bulent, Baris, et al., 2010). On the contrary, landscape metrics calculated for the agricultural landscape interpret the tool for change assessment in consequence of agricultural transition from traditional to productivist and postproductivist regimes. Understanding the process of agricultural change could enhance the role of agricultural policy as a tool for landscape management and regional planning (Zomeni, Tzanopoulos, Pantis, 2008).

The analysis of the structural landscape changes proved to be an important aspect of landscape functions'changing (Walz, 2005).

In its variability, the landscape structure is associated with the dynamics of natural and anthropogenic processes that condition such dynamics and are simultaneously represented in landscape through it. Taking into account the increasing frequency of extreme natural phenomena in the last years, attention is more often paid to possibilities of improvement or 
revitalization of natural stabilization functions, processes and landscape elements that have been altered or fully eliminated due to anthropic activities.

\section{Delineation of the territory and methodology of solution}

The objective of research was the analysis of landscape structure in selected time horizons for three model territories in Czech Republic differing in their development and use. The territories were agricultural landscape of the Dolnomoravký úval lowland with intensive farming (Hustopeče microregion - selected cadastres), landscape of the Českomoravská vrchovina Uplands (Žejbro brook watershed - selected cadastres) and landscape in the protected zone of a water source (watersheds of the Maršovský and Jedlovský brooks adjacent to the Hubenov water reservoir - selected cadastres). The delineation of the territory and/or the area amounting to tens of square kilometres was conceived with respect to the scale of historical documentation (maps, Earth Remote Sensing - ERS), certain complexity and representativeness of the territory with a possibility of mutual comparison.

Landscape structure analysis has been realized in the Hustopeče microregion - selected cadastres in selected time period: 1825, 1968, 2006. The year 1968 has been chosen with respect to drainage build-up. Within the frame of Research Plan of RISWC MZE 0002704902 solution, there are analysed landscape structure, landscape functions and drainage of this region together. From that point of view, the year 1968 is important date enabling comparison of parameters (landscape metrics) before and after subsurface drainage building-up.

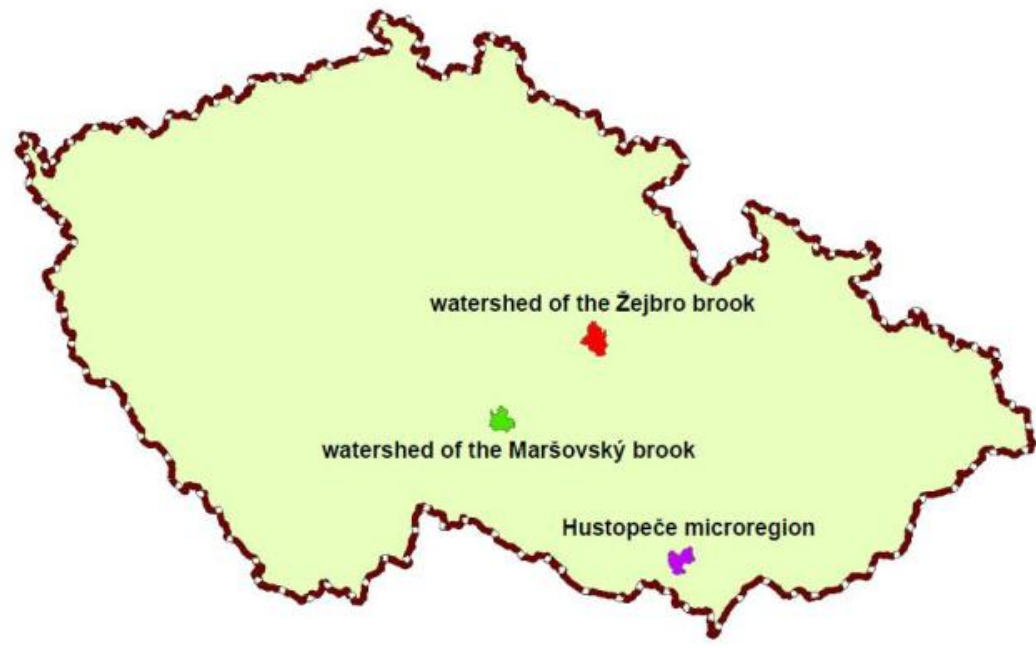

Fig 1. Delineation of case territories within the Czech Republic.

Model territories were selected taking into account the continuity of the solution in experimental watersheds and areas of the Research Institute for Soil and Water Conservation that were maintained for a long time, availability and possibilities of obtaining essential background materials for these territories with respect to the solution, and the distance of these territories from the aspect of field surveys.

Considering the scope of the study, the selection was conditioned particularly by assumed changes in landscape structure and by the development of its arrangement in relation to changes in land use in the course of selected time horizons (Hustopeče microregion, Žejbro). In addition, the territory of Hubenov water reservoir was selected in order to reveal whether and how different management in this territory pursuing its specific objectives (water resource, protection zones) influenced the landscape structure.

The selection of time horizons for the analysis of landscape structure consisted of three time series in order to describe crucial changes in landscape and/or landscape structure from ancient times to the present. 
The time of stable cadastre mapping from the first half of the $19^{\text {th }}$ century (1825) at a $1: 2880$ scale was selected as the initial period. The present situation (2006) at a 1:5000 scale or coloured orthophotos from 2006 are at the opposite end of the time span. The period between these two ends is covered by the selection of historical black-and-white aerial photographs from the sixties of the $20^{\text {th }}$ century (1968) at a scale $1: 10000-1: 38000$.

Presented outputs are a result of activities realized in 2009 - 2010 in several basic steps:

- procurement of map documentation (maps of stable cadastre) and materials of ERS (historical black-and-white aerial photos and coloured orthophotos) for the selected territories of interest in the required time periods

- georeferencing and orthorectification of these materials into the coordinate system for a subsequent use in GIS environment (ArcGIS - Arclnfo)

- manual digitization (construction of vector map layers of Land Use/Land Cover) above these grids at a 1:2000 scale and addition of the ID attribute bearing information on LU/LC according to the newly proposed legend common to all territories, time series

- creation of structured digital database in GIS environment as Personal Geodatabase

- analysis of landscape structure in GIS environment

- construction of map outputs and their appendixes (graphical, tabular data).

\subsection{Analysis of landscape structure by means of the computation of landscape ecological indexes}

The analyses were performed in ArcGIS environment using standard tools and extension tools, specially developed for the analysis of landscape structure. These were Vector Based Landscape Analysis Tools Extension for ArcGIS (V-LATE) and Patch Analyst. Both extensions are freely available and compatible with ArcGIS tools while the range of calculated indexes and generated values are more or less identical and comply with the assumption of limitless use of both these tools to obtain required results.

The calculations of landscape structure indexes are generated as a new column or several columns in the attribute table of a polygon layer and/or as external tables with computed indicators on two levels: separately for partial (selected) categories (Class Analysis) and in total for all categories included in the analysis (Landscape Analysis). Computed coefficients (indexes) can be classified according to the type of evaluated characteristic into the categories of indexes of shape, size, diversity, proximity, edges and statistical indicators.

The defined method of computations of landscape ecological indexes in the analysis of landscape structure was performed for LU/LC classes in identified categories, spatial and compositional relations of landscape elements - patches, corridors, matrices. The results of performed analyses are presented as map outputs and their appendixes.

There is number of metrics available to quantify landscape structure, but their statistical properties and behavior across a range of classification schemes and landscapes, as well as their sensitivity to changing landscape patterns, are still not fully understood (Huang, Geiger, Kupfer, 2006).

Clarification of interrelationships and redundancy is needed to guide metric selection and interpretation for the purpose of landscape monitoring. Landscape metrics can be identified in the class- and landscape-level structure and universality, strength, and consistency of the identified landscape structure components can be calculated. The results of number of studies indicate there are consistent combinations of metrics that universally describe the major attributes of landscape structure at the class- and lands cape-levels (Cushman, McGariyal, Neel; 2007). 
Some of the landscape metrics may be correlated with each other and can have different sensitivity depending on spatial resolution (Yang, Liu, 2005).

Results of some studies indicate that many metrics behaved predictably with increasing classification detail, increasing or decreasing at rates that were often relatively similar and independent to sensor and landscape pattern. At lower class numbers, metrics were most sensitive to increasing classification detail, and the effects of classification scheme were most erratic and sensitive to resolution and underlying landscape pattern. Overall, it provides a descriptive overview of the sensitivity of common metrics to changes in classification scheme, as well as a first attempt to draw some generalizations about the importance of classification scheme in conjunction with resolution effects (Huang, Geiger, Kupfer, 2006).

Another aspect of landscape metrics is based on the patch mosaic paradigm, in which landscapes are conceptualized and analyzed as mosaics of discrete patches. While this model has been widely successful, there are many situations where it is more meaningful to model landscape structure based on continuous rather than discrete spatial heterogeneity. The growing field of surface metrology offers a variety of surface metrics for quantifying landscape gradients. Surface properties could have potential to offer new insights into landscape pattern-process relationships (Oguz, Zengin, 2011).

Landscape metrics can be a useful indicator in land use change analysis and are vital for integrated landscape evaluation (Yu, $\mathrm{Ng}, 2006)$.

\subsubsection{Proximity analysis (index)}

This analysis is one of the distance analyses that are used to determine the mutual proximity of objects of a given value. In this case it is the proximity of objects of the same LU/LC category computed by the nearest neighbor method. The results are entered into three new columns of the attribute table of each object (polygon): 1. A distance to the nearest object of the given category (if it equals zero, the objects have a common edge, they are contiguous to each other), 2. The identification number of the nearest object of the same category, 3 . The area of the nearest object of the same category. The map representation of computed values of proximity analysis provides an overview of the distribution of particular LU/LC categories and of the way (type) of their distribution in the territory. The table summarizing statistical data on selected attributes for LU/LC categories is a part of any map sheet: number of patches (Cnt_Description), NNDist distance (minimum, maximum, mean), categories of NNDist distance (minimum, maximum, sum of patches belonging to the given category).

Graphical representation of other indicators computed by the analysis of landscape structure that are connected with the spatial arrangement of areas of the particular LU/LC categories is also a map sheet appendix of these map sets.

These characteristics are presented as results of the analysis of landscape division that solves landscape splitting by means of landscape division indexes, and the scale, mesh fineness in landscape by means of the index of effective mesh size. 

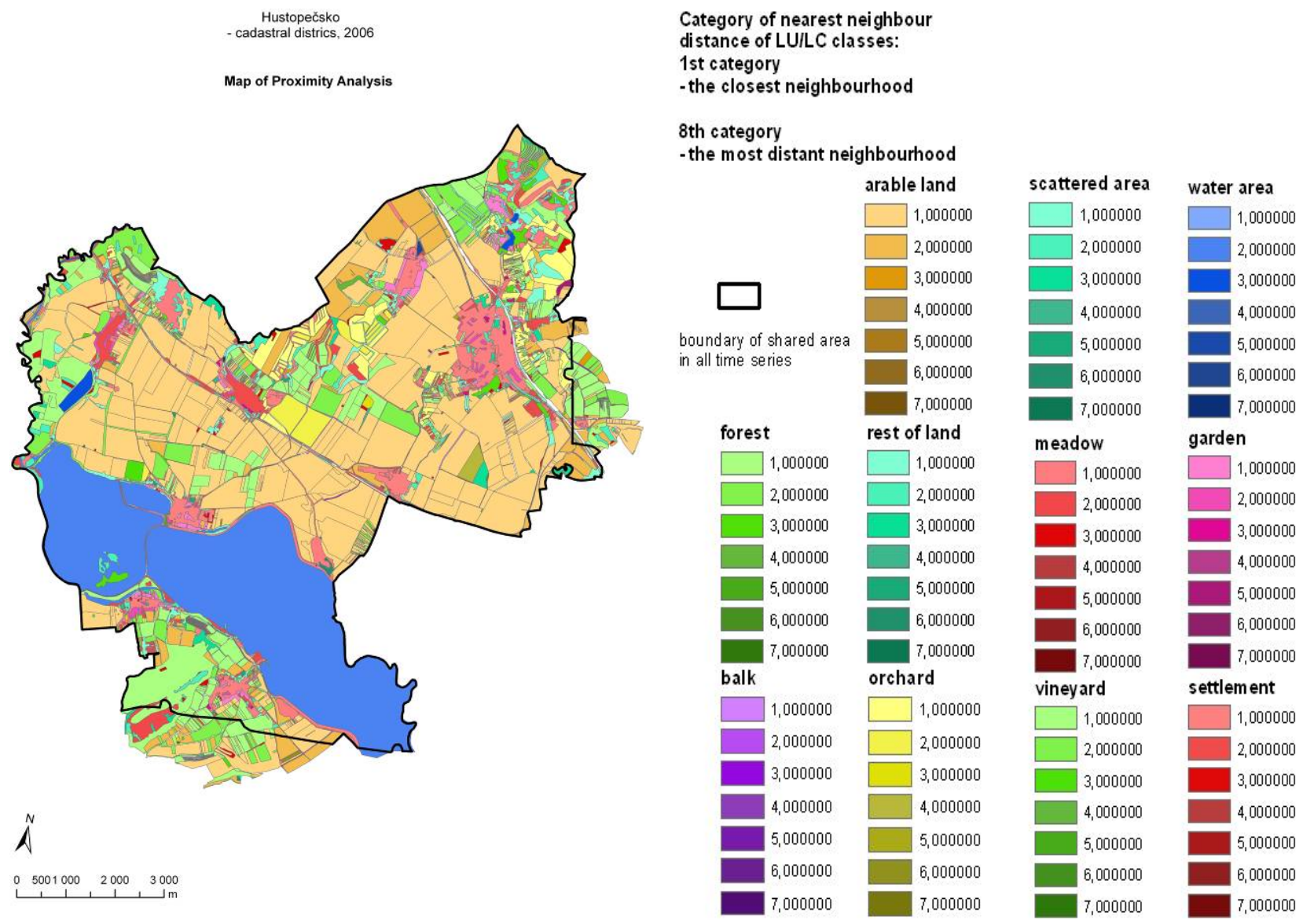

Fig 2. The map of proximity analysis (Hustopeče microregion, 2006).

\subsubsection{Patch area analysis (index)}

It is one of the basic spatial analyses while it is an initial information input for a number of extension analyses that figures in computation algorithms of consecutive analyses of landscape structure. Using the patch area analysis it is possible to describe the landscape graininess on a scale from very fine, fine, medium to coarse graininess. In addition, the patch area plays a very important role as a variable influencing the species composition, diversity and land cover. These indicators are computed for the particular LU/LC categories included number of patches, total patch area, average patch area of the given category and standard deviation in the analysis. The total number of patches of all categories and their total area are computed on the level of landscape analysis.

Graphs of two statistically processed indicators of this analysis are also a part of each map sheet: patch area and average patch area. Other computed indicators are graphically represented in the map sheet appendix. These indicators are number of patches and ratio the ratio of areas of the given category to total area. 


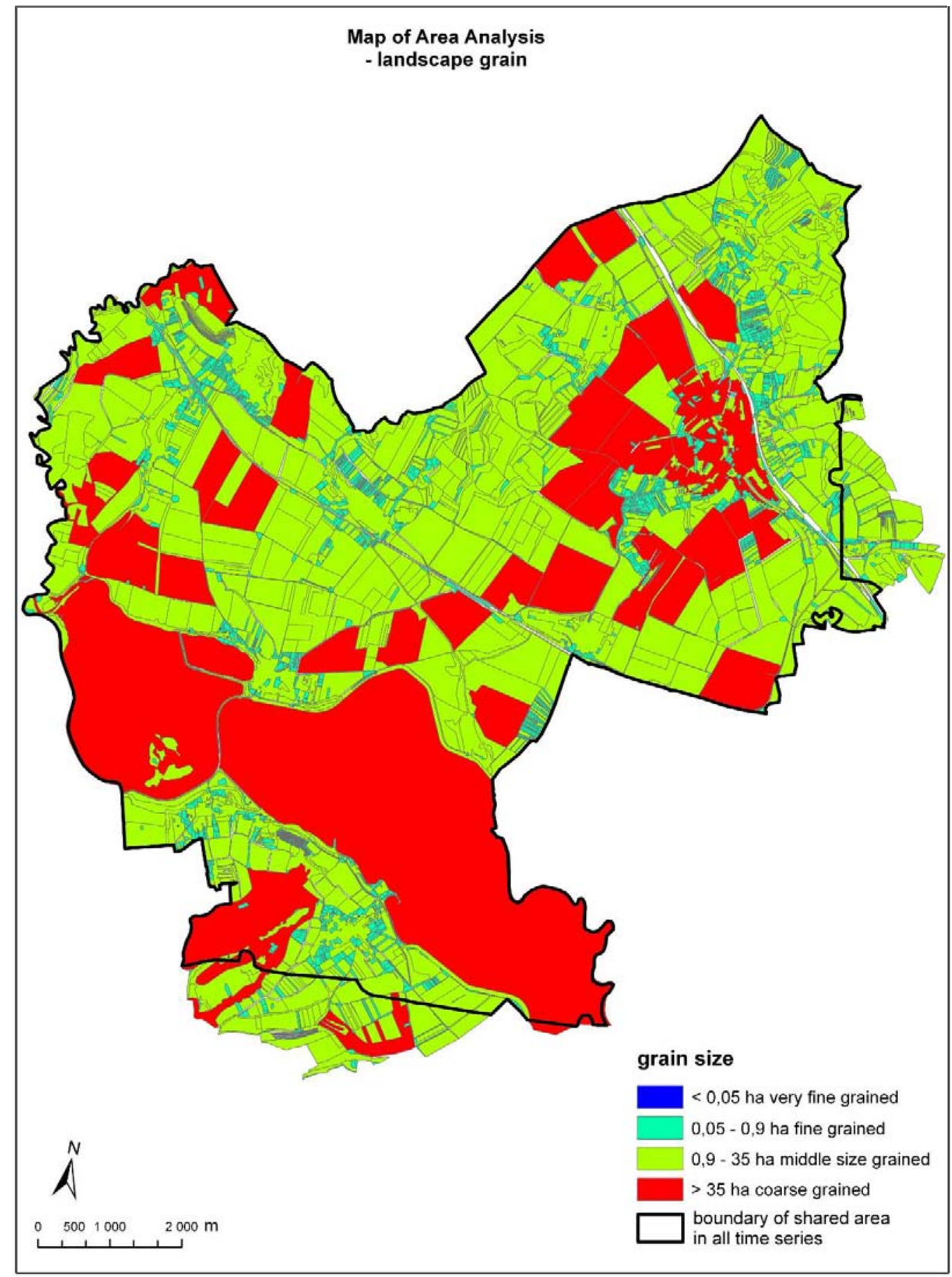

Fig 3. The map of patch area analysis (Hustopeče microregion, 2006).

\subsubsection{Shape analysis (index)}

It is one of the other metric analyses of landscape space that describe temporal landscape changes in the best way. These indicators are computed for the particular categories: number of patches, average shape of patch, perimeter-area ratio, average fractal dimension. Shape Idx patch shape, PAratio - perimeter-area ratio and Frac Dim - fractal dimension, expressing the level of shape diversity of patches, are newly entered columns into the attribute table of the polygon layer of LU/LC categories. 


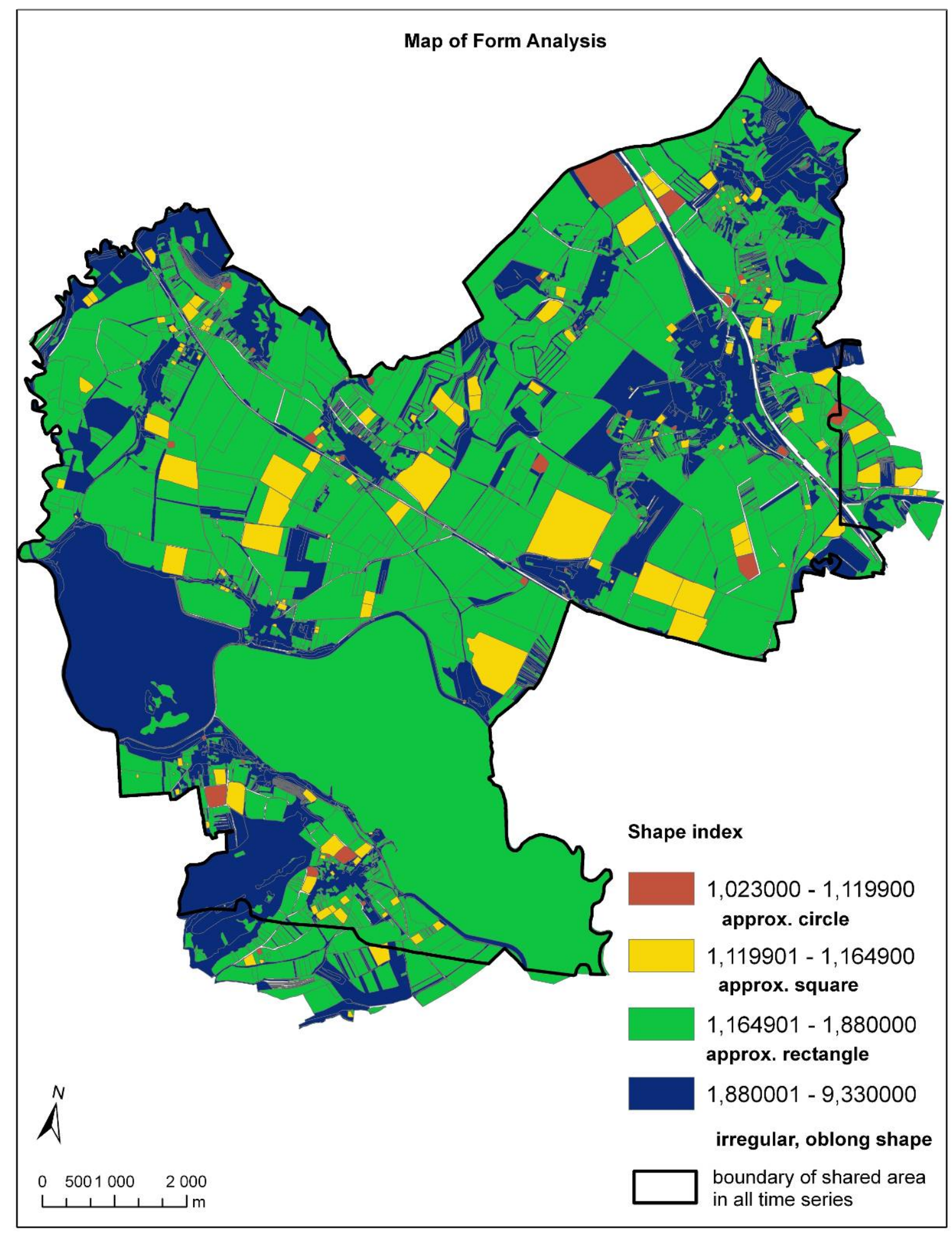

Fig 4. The map of patch shape analysis (Hustopeče microregion, 2006).

On the level of landscape analysis the total value of all above described variables is computed for all categories in total. The shape indexes are important from the aspect of landscape division or on the contrary, of geometrization of spatial structures. The higher the value of the shape index, the more complicated the shape of patches and their edges become longer. On the other hand, the lower the index, the simpler the shape, which can be described by basic geometric shapes, and which expresses simplification, consolidation of the particular patch shapes. In this context shape characteristics are important from the aspect of the edge effect and functions the vector of which it is in landscape. The role of the edge effect increases with the increasing presence of heterogeneous patches in landscape and with their more complicated, irregular shape. 
The table summarizing statistical data on selected attributes for LU/LC categories is a part of each map sheet: number of patches (Cnt_Description), shape index (minimum, maximum, mean) and a graph of the average patch shape index. Other computed indexes are graphically represented in the appendix of map sheets. It is the index PAratio - perimeter-area ratio and average fractal dimension.

\subsubsection{Diversity analysis (index)}

It is aimed at the evaluation of richness and diversity of analysed patches. Within the particular categories the computation generates the total number of patches of each category, their total area and the index Ratio - the ratio of areas of the given category to total area. On the level of landscape analysis, absolute and relative richness is determined according to the number of categories included in the computation and the following indexes are computed: the indexes expressing the richness of patches (Shannon's diversity index), evenness - distribution and density of patches (Shannon's evenness index) and dominances.

Graphically represented outputs of edge analysis are a part of map sheets. It is a more specific analysis focused on edge and/or ecotone effect. On the level of class analysis these indexes are computed for the particular LU/LC categories: total edge index of the particular categories, its average value and number of patches of the given category. On the level of landscape analysis, edge density, total edge index and its average value for all categories included in the analysis are computed. The computation of these indexes is important for the evaluation of landscape heterogeneity and contrast. 


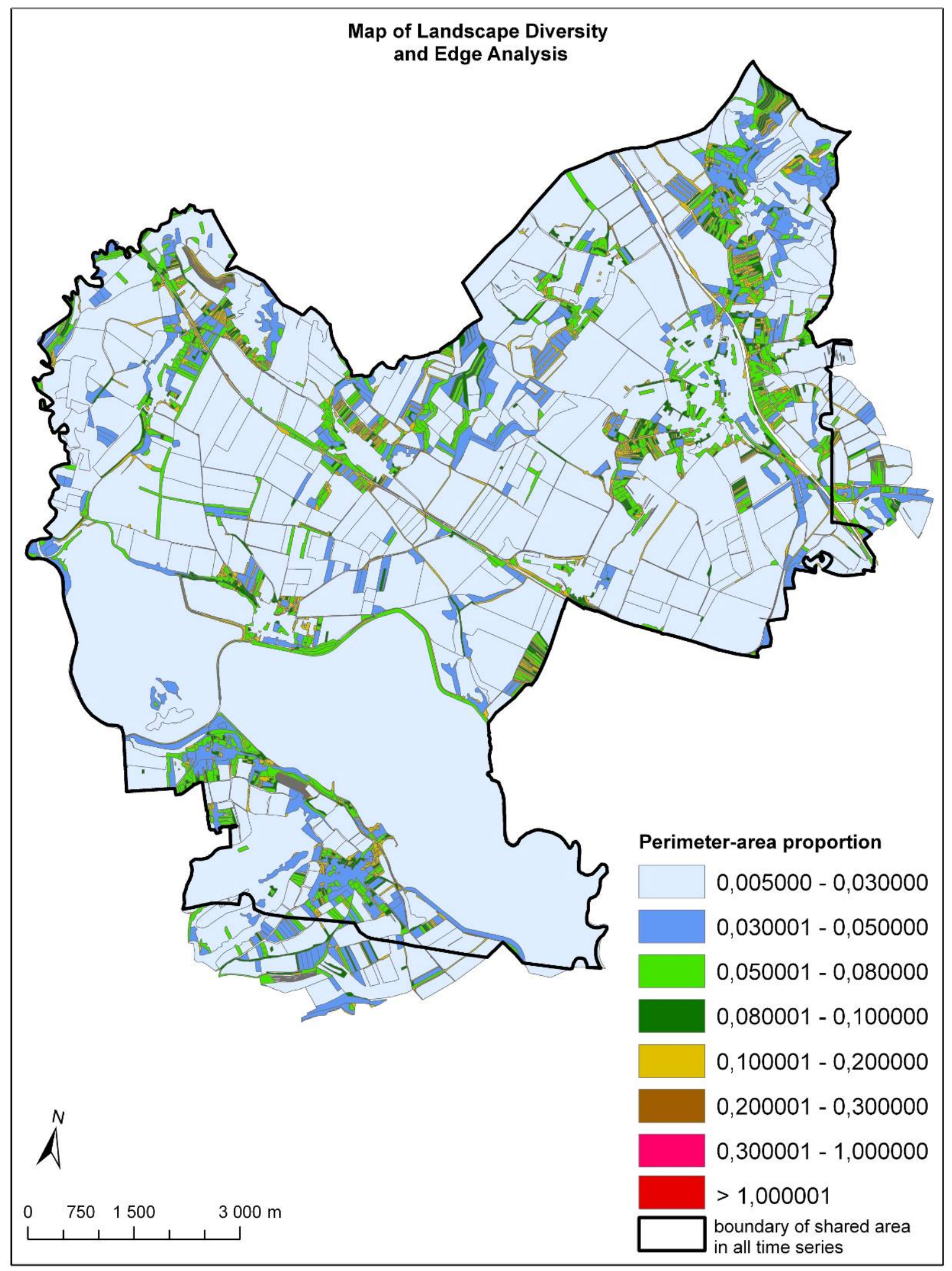

Fig 5. Diversity map (Hustopeče microregion, 2006).

\section{Description}

Specific features of the particular time horizons - interpretation of the results of landscape structure analysis. The most pronounced features and characteristics of landscape structure are described in the text below. They are determinative and important for the particular time periods. The description is based on the statistical processing of all analysed indexes in resultant tables, figures and maps. Their presentation is relatively extensive; therefore, 
the following description is focused on specific features, not on a detailed interpretation of all computed values.

\subsection{The year 1825 - stable cadastre}

Typical pattern of the Hustopeče territory is the pronounced line structure of very narrow strips of patches of very fine graininess, very low porosity, and considerable, almost complete connectivity characteristic of croft management. This reality is reflected in the characteristics of edge effect while the edge density exceeds the values of later time periods several times. The distribution of patches of the other LU/LC categories is markedly clumpy, bound to the water-course and adjacent floodplain forests and wetlands. Therefore it is a highly contrast landscape, with diametrically different diversity and heterogeneity. The landscape is characterized by a high number of patches belonging to the category of arable land. It demonstrates the long-term, permanent use of this territory for agricultural production. Arable land is a major category of this territory. The other most numerous patches categories are vineyards and permanent grasslands. In the framework of the studied categories forests are also important but taking into account the patch distribution in the territory it is a pronounced clumpy distribution of a few patches of large area. The average size of patches of all categories is lower by 1 order of magnitude compared to the later time periods while the highest values are reached in the category of arable land. For some places it was not possible to provide adequate data bases. These places are on the map as "no data". 


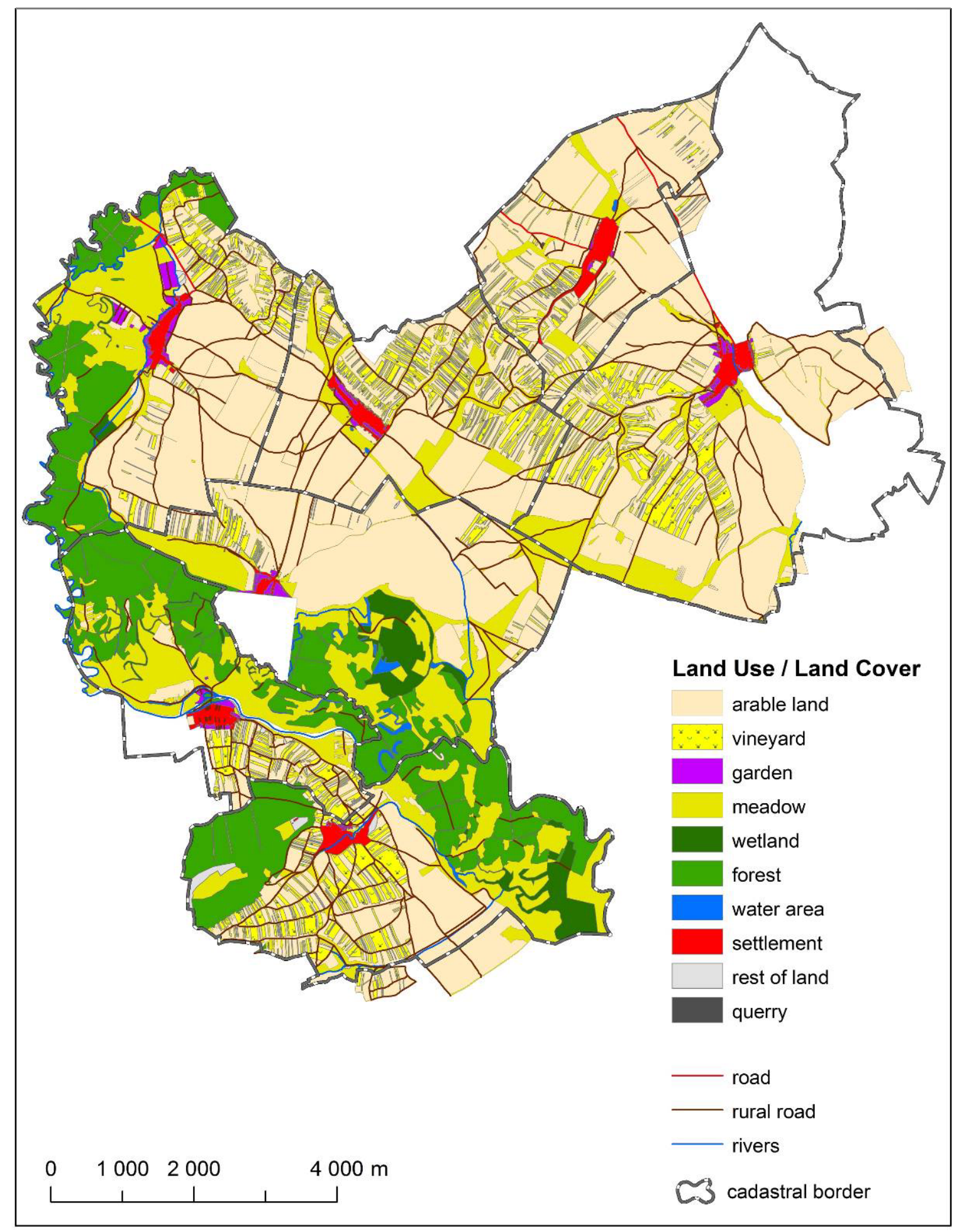

Fig 6. The map of land use (Hustopeče microregion, 1825).

\subsection{The sixties - black and white aerial photographs}

In the subsequent time period the basic features of the landscape composition from the mid- $19^{\text {th }}$ century can be traced in fragments at least, nevertheless, a pronounced shift of all metric characteristics of areas occurred: from narrow strips to rectangular areas of huge size. Compared to the preceding period the number of patches decreased by $1-2$ orders of magnitude (arable land) while the area of arable land and water bodies increased at the cost of PGL (permanent grassland) and wetlands. There was a crucial change in the mosaic pattern of landscape - an enlargement of the landscape grain and a decrease in mesh density by 1 order of magnitude. The highest value of the average edge was reached, which was higher than in 
2006, when the landscape structure underwent refinement in the categories covering agricultural land. Hence the blocks of arable land reached their maximum area in that period. It was also reflected in the shape characteristics: smooth shape was dominant, geometric shapes of landscape matrix.

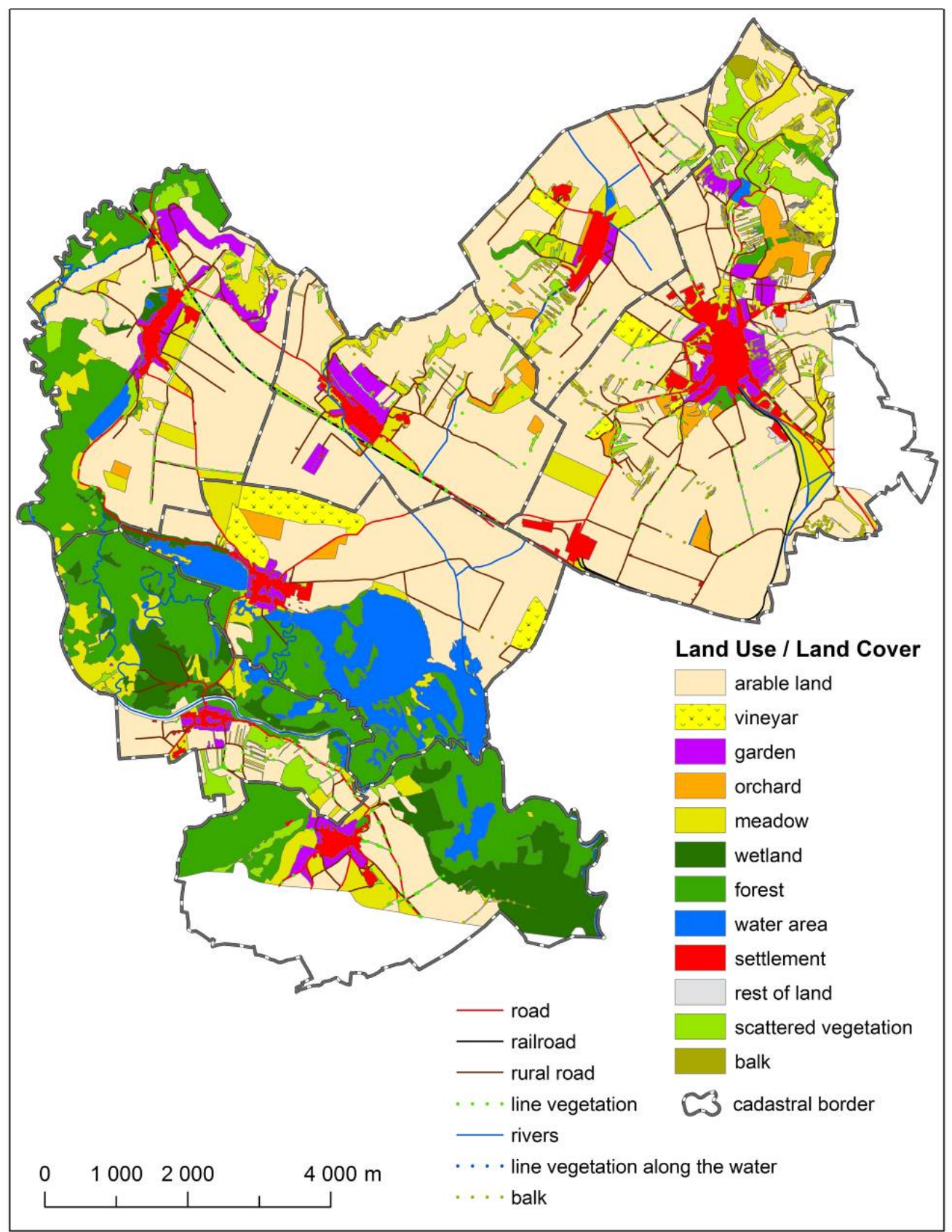

Fig 7. The map of land use (Hustopeče microregion, 1968).

\subsection{The present situation - coloured orthophotos}

This period was characterized by the most pronounced change in landscape structure when the area of water bodies increased several times after the construction of the hydraulic structure Novomlýnské nádrže. The water bodies were enlarged at the cost of forests, PGL while wetlands were damaged almost completely. This intervention caused crucial changes in the landscape structure of non-agricultural land. On agricultural land there was a significant increase in the vineyard ratio, which led, among other things, to the division and refinement of the landscape matrix mosaic compared to 1968. Similarly like in the preceding periods, the clumpy distribution of components in the landscape space was maintained, while it was accentuated by an increase in the landscape matrix contrast in this period. 


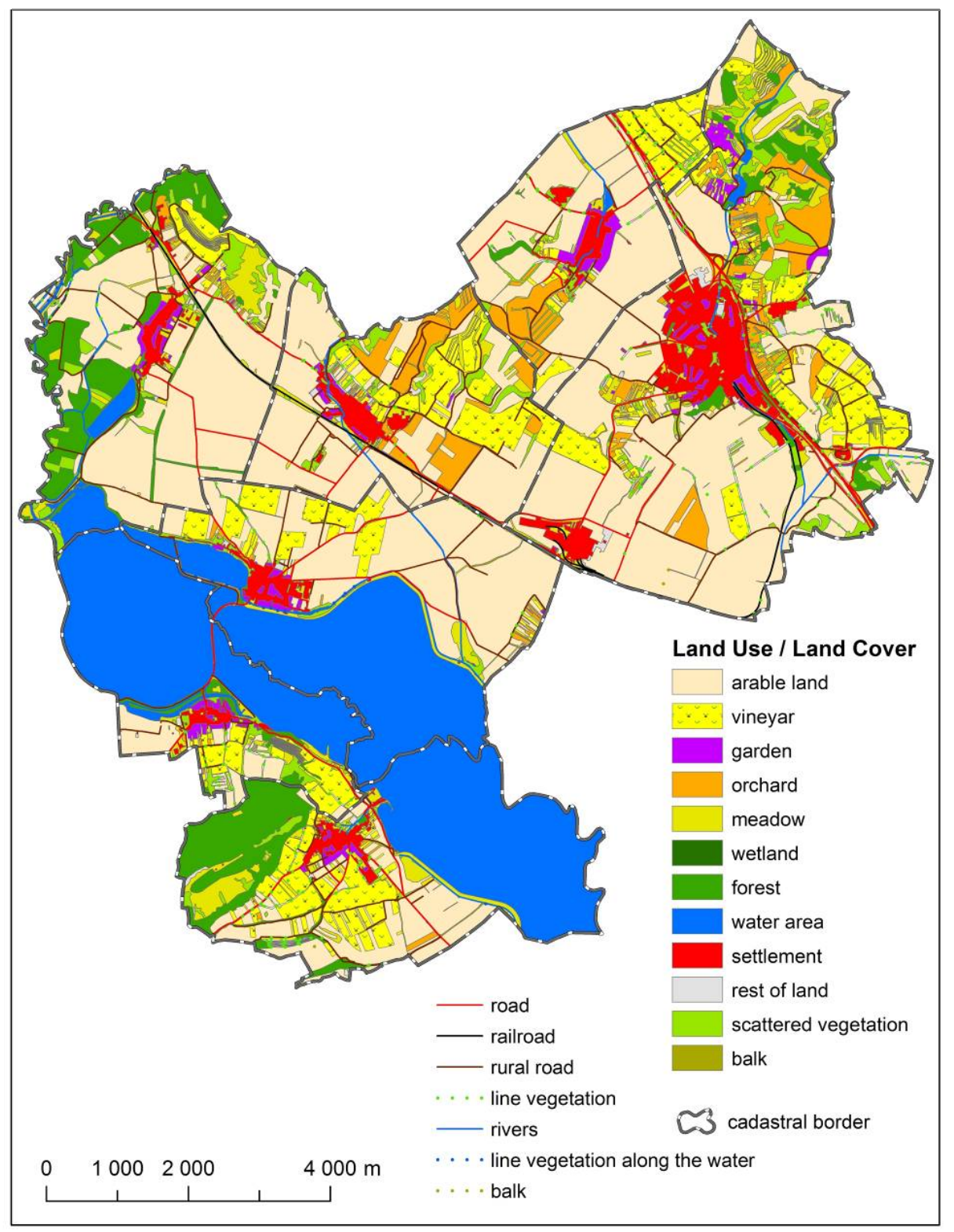

Fig 8. The map of land use (Hustopeče microregion, 2006).

Arable land can be designated as landscape matrix thanks to its dominance by the area and number of polygons. It implies the character of the territory with prevailing land use for intensive agriculture. Generally, the development of landscape structure has corresponded to the expected trend reflecting social and economic development in the period from 1825 to the present. It has been the process of a gradual reduction in the number, division and richness of areas under simultaneously increasing geometrization, unification and simplification of structures, enlargement of the landscape grain and coarseness of the scale. This trend is generally applicable to all regions of the CR that belong to the type agricultural and agriculturalforest landscape. The effective mesh size is different by 1 order of magnitude in the period of stable cadastre and in the $20^{\text {th }}$ century. Radical simplification of landscape structure, reduction, geometrization and a change in spatial arrangement in comparison with the stable cadastre (for the evaluation of the initial situation for this study) and great economic pressure have contributed to the flattening of non-production functions of landscape.

Landscape patches configuration differs significantly through the selected time period: 1825 typical sharp line structure of very tight patch stripes of arable land with very small grain-size, very low porosity and almost total connectivity. Configuration of patches from the other categories LU/LC is markedly clustered in relation to the water course with riparian woodland and wetlands. That is why the Hustopeče microregion is highly contrasting with diametrically 
varied landscape diversity and heterogeneity. These basic characteristics are recognizable at least in fragments in the following time periods too, but with very strong reduction of all patch metrics: very tight patch stripes turned to very large rectangular matrix.

\subsection{Selected trends of a change in land use (see Fig. No. 9):}

Arable land: a decrease from $51 \%$ to ca. $42 \%$ at present (a reduction in the number of patches by ca. $46 \%$ ), the landscape grain (landscape matrix) has enlarged several times

Permanent grassland (PGL): a decrease from $19.8 \%$ to ca. $5.5 \%$ (a difference in PGL percentage is $14.3 \%$ compared to the stable cadastre, at a 9 -fold reduction in the number of patches), the downward trend continues.

Wetlands: the territory had $4.5 \%$ of wetlands in 1968 (more than in the stable cadastre period), at present it is $0 \%$.

Forest: $14.3 \%$ in the stable cadastre period (on 216 areas), still $14.3 \%$ in 1968 (on 56 areas only), $6.9 \%$ of forest at present (on 71 areas) - a decrease to a half (a reduction in areas by two thirds), creation of large forest complexes.

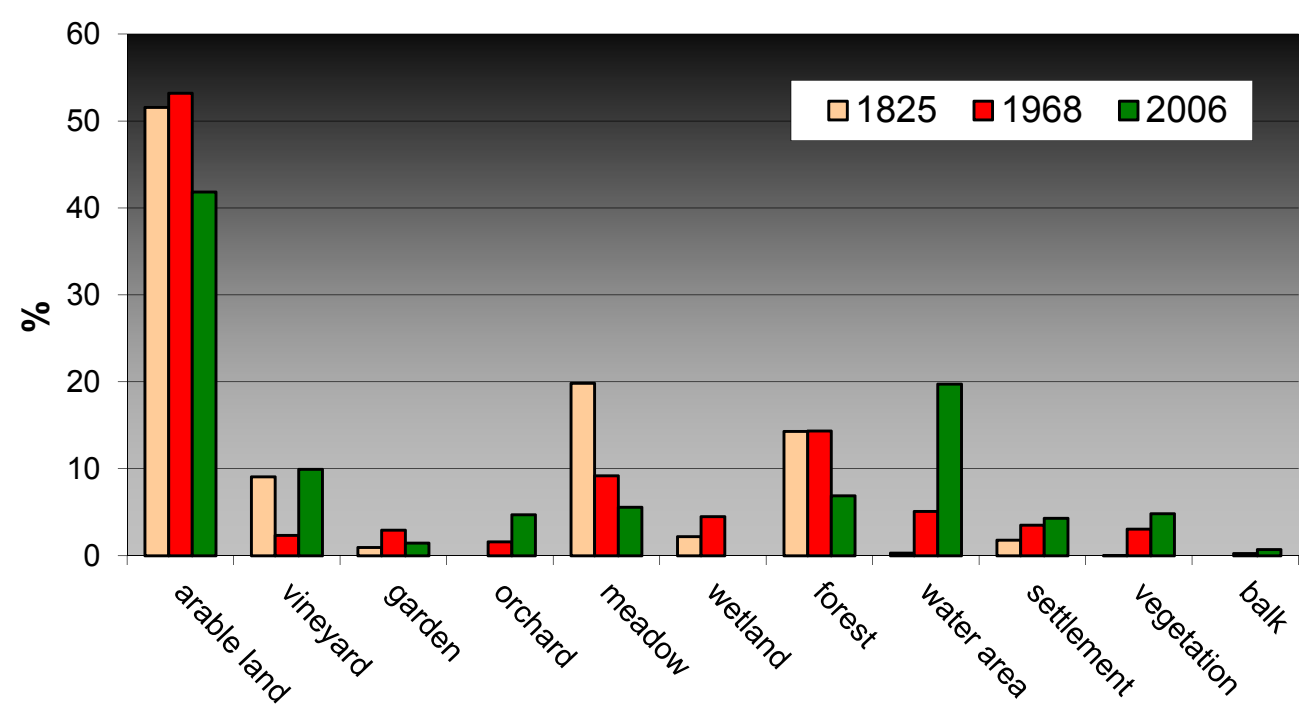

Fig 9. Changes in land use in the studied years.

Water bodies: an increase in their percentage by more than $19 \%$ while the areas decreased by ca. $6 \%$ (a specific feature of Hustopeče microregion - the Nové Mlýny water reservoir was constructed at the cost of forests, wetlands and PGL).

Balks: an increase from $0.2 \%$ to $0.7 \%$ (three times), the number of areas increased to 81 at present (an upward trend).

Scattered green vegetation: an increase from $3.0 \%$ in the sixties to $4.8 \%$ at present (an increase by almost $2 \%$ ). The number of areas increased by $67 \%$ (an upward trend of small areas).

\section{Discussion}

The analysis of landscape structure and processing of its results as map outputs provide specific original data for the implementation of objectives planned in the region of evaluation of changes in landscape functions and evaluation of changes in the rural space. It is a thematically comprehensive set of background data (geo-databases) that can be applied both in the field of research and in the sphere of public administration (land-use planning, land consolidation, etc.).

The hitherto solution to the problem of the analysis of landscape structure for selected territories in the time span encompassing the present and historical situation corresponds to the assumptions of acquisition of effective data applicable in the process of land use and 
landscape planning. The used maps and remote sensing materials provide, in spite of some difficulties, a very valuable source of unique and crucial information that will influence the future character, functions and quality of our cultural landscape. Digital processing of the acquired information complies with contemporary methods of work with data ensuring a possibility of constructing maps and statistical outputs according to the requirements of land-use planning documentation. Processed analytical data and computed landscape ecological indexes can be corrected according to specific realizations in practice, e.g. processing of a selected detailed territory, change or selection of another attribute of the analysis, overlay analyses in the required range of characteristics, territories and time periods, etc.

\section{Conclusions}

The present proposals of long-term measures in planning documentations [of complex land consolidation and functional use (land-use plan)] are developed without fundamental assessment of development of the landscape structure of a specific territory.

Historical background materials (aerial photographs, historical maps) are an invaluable and underestimated source of information for complex land consolidation, land-use plans while this information should be used to a larger extent in the future.

It is not possible to return to the historical situation but mainly in some types of landscapes or in the territory with an emphasis on other aspects of land use than production ones we can apply available knowledge for the fulfillment of non-production functions of landscape.

The processed analytical data can be used for the preparation of specific realizations of measures in practice: e.g. the design of a selected detailed territory in complex land consolidation and/or modification of the functional use of a specific territory.

The understanding of spatial configuration and its development in the context of anthropic activities brings about better conditions for interpretation and prediction of the landscape functional potential with all consequences influencing these activities retroactively. The evaluation of trends makes it possible to choose a "mean" solution to a proposal of the new arrangement and functional use of landscape in the territory in question (the optimum landscape structure can be defined by means of the approximation of characteristics of landscape structures taking into account non-production functions of landscape).

Based on the knowledge acquired by the solution of the above described problem and experiences from consultations with experts in land-use planning and land consolidation, the elaboration of methodology for the Coordination of Land-use Planning and Complex Land Consolidation was initiated in cooperation with Ministry of Regional Development of the CR (Institute for Spatial Development) and Ministry of Agriculture of the CR (Central Land Office, Research Institute for Soil and Water Conservation). The methodology was gradually elaborated in the years 2009 and 2010, currently it is put up on the website of the Institute for Spatial Development and Ministry of Agriculture, its certification has been approved by the competent body of state administration (Central Land Office) and it is in print now.

\section{Acknowledgement}

This contribution was written on the basis of outputs obtained during the solution of Research Plan of the Research Institute for Soil and Water Conservation of the Ministry of Agriculture of the Czech Republic 0002704902 "Integrated Systems of Soil, Water and Landscape Conservation and Use in Agriculture and Rural Development", its partial projects "Analysis of Historical Changes in Landscape Structure including HMS by means of ERS" and "Evaluation of Changes in Rural Space Caused by Measures of Complex Land Consolidation and Land-use Planning" and Research Project of the Ministry of Agriculture of the Czech Republic NAZV Q192A012. 
[1] Boližiar, V., Brůna, V. \& Křováková, K. (2008): Potential of antique maps and aerial photographs for landscape changes assessment - an example of the High Tatra Mts. Ekológia/Ecology, 27(1), 65-81.

[2] Cushman, S. A., McGariyal, K. \& Neel, C. (2007). Parsimony in landscape metrics: Strength, universality, and consistency. Ecological Indicators 8(5), 691-703. http://apps.webofknowledge.com/full_record.do?product=WOS\&search_mode=MarkedList \&qid=12\&SID=Z1HIkEdK8GDoCdkkkEe\&page=1\&doc=31\&colName=WOS Doi: 10.1016/j.ecolind.2006.08.001.

[3] Hayriye, E., Bulent, D., Baris, K., et al. (2010). Analyzing landscape changes in the Bafa Lake Nature Park of Turkey using remote sensing and landscape structure metrics. Environmental Monitoring and Assessment 165(1-4), 617-632. Doi: 10.1007/s10661-0090973-y.

[4] Fladmark, J., Mulvagh, G. \& Evans, M. (1991). Tomorrow's Architectural heritage: Landscape and Buildings in the Countryside. Edinburgh and London:Mainstream Publishing.

[5] Forman, R.T., Godron, M (1993).Krajinná ekologie. Praha: Academia

[6] Girel, J., Barguet-Duport, B. Pautou, G. (1997). Landscape Structure and Historical Processes Along Diked European Valleys: A Case Study of the Arc/lsere Confluence (Savoie, France). Environmental Management. 21(6), 891-907.

Doi: $10.1007 / \mathrm{s} 002679900075$.

[7] Guth, J. \& Kučera, T. (1997). Monitorování změn krajinného pokryvu s využitím DPZ a GIS. Príroda Nr. 10, 107-124.

[8] Hais, M., Brom, J. \& Pecharová, E. (2006). Evaluation of Landscape Changes by Remote Sensing. Životní Prostředí, 40(2), 80-83.

[9] Huang, C., Geiger, E. \& Kupfer, J. (2006). Sensitivity of landscape metrics to classification scheme. International Journal of Remote Sensing. 27(14), 2927-2948. Doi: $10.1080 / 01431160600554330$.

[10] Jian-hua, X., Yan, L., Nan-shan, A. \& Wen-ze, Y. (2001). A study on landscape mosaic structure in urban-rural area in Northwest of China with RS and GIS. Chinese Geographical Science 11(4), 366-376. Doi: 10.1007/s11769-001-0053-x.

[11] Juhás, I. (1991). Metódy diaĺkového prieskumu Zeme pri tvorbe krajinno-ekologických podkladov. Záhrada - Park - Krajina 1(2), 17-19.

[12] Kamusoko, C. \& Aniya, M. (2007). Land use/cover change and landscape fragmentation analysis in the Bindura District, Zimbabwe. Land Degradation \& Development. 18(2), 221233. Doi: $10.1002 / \mathrm{ldr} .761$.

[13] Kubeš, J. \& Mičková, K. (2003). Development of horizontal landscape structure in the Pohořsko region (the Czech-Austrian frontier) between 1938 - 2000. Ekologia/Ecology 22(3), 269-283.

[14] Lipský, Z. (2000). Sledování změn v kulturní krajině. Praha: Czech University of Life Sciences.

[15] Lipský, Z., Romportl, D. (2006). Krajinné indikátory pro hodnocení změn krajinného rázu (pp. 51-56). In Voreil, I. \& Sklenička, P., eds., Ochrana krajinného rázu - třináct let zkušeností, úspěchů i omylů. Praha: Czech University of Technology, Czech University of Life Sciences, Ministry of Environment of the Czech Republic.

[16] Delin, L., Bicheng, L., Xianzhao, L. \& Warrington, D. H. (2011). Monitoring land use change at a small watershed scale on the Loess Plateau, China: applications of landscape metrics, remote sensing and GIS. Environmental Earth Sciences 64(8), 2229-2239. Doi: $10.1007 / \mathrm{s} 12665-011-1051-7$. 
[17] Oguz, H. \& Zengin, M. (2011). Analyzing land use/land cover change using remote sensing data and landscape structure metrics: a case study of Erzurum, Turkey. Fresenius Environmental Bulletin. 20(12a), 3258-3269.

[18] Pérez-Soba, M. \& Wascher, D. M., eds. (2005). Landscape Character Areas. Places for building a sustainable Europe. [Policy Brochure as deliverable from the EU's Accompanying Measure project European Landscape Character Assessment Initiative (ELCAI), funded under the $5^{\text {th }}$ Framework Programme on Energy, Environment and Sustainable Development]. Wageningen.

[19] Špulerová, J. (2008). Land use changes in the Veselovianka river catchment in the Horná Orava region. Ekológia/Ecology 27(3), 326-337.

[20] Walz, U. (2008). Monitoring of landscape change and functions in Saxony (Eastern Germany) - Methods and indicators. Symposium on Ecological Indicators at Multiple Scales Montreal, Canada. Ecological Indicators 8(6), 807-817. Doi: 10.1016/j.ecolind.2007.09.006.

[21] Wang, Z. \& Yin, Q. (2011). Land use and landscape pattern changes in Nanjing during 1988-2007 (pp. 680-683). In Geoscience and Remote Sensing Symposium (IGARSS), 2011 IEEE International. Doi: 10.1109/IGARSS.2011.6049221.

[22] Yang, X. J. \& Liu, Z. (2005). Quantifying landscape pattern and its change in an estuarine watershed using satellite imagery and landscape metrics. International Journal of Remote Sensing. 26(23), 5297-5323. Doi: 10.1080/01431160500219273.

[23] $\mathrm{Yu}, \mathrm{X} ., \mathrm{Ng}, \mathrm{C}$. (2006). An integrated evaluation of landscape change using remote sensing and landscape metrics: a case study of Panyu, Guangzhou. International Journal of Remote Sensing 27(6), 1075-1092. Doi: 10.1080/01431160500377162.

[24] Zhang, L., Kong F., Sun, Z., et al. (2010). Evaluation of the Land-use Suitability of Jinan City Based on GIS and Landscape Metrics. In $18^{\text {th }}$ International Conference on Geoinformatics. Beijing: Peking University.

[25] Zomeni, M., Tzanopoulos, J. \& Pantis, J. (2008). Historical analysis of landscape change using remote sensing techniques: An explanatory tool for agricultural transformation in Greek rural areas. Landscape and Urban Planning. 86(1), 38-46. Doi: 10.1016/j.landurbplan.2007.12.006.

[26] Zonneveld, I. S. (1979). Land Evaluation and Land(scape) Science. Enschede: International Training Center. 